\title{
Small bowel review - Part II
}

\author{
ABR THOMSON MD PhD FRCPC FACG, E JAROCKA-CYRTA MD PhD, J FARIA MD, GE WILD MDCM PhD FRCPC FACP
}

\begin{abstract}
ABR Thomson, E JarockA-Cyrta, J FARIA, GE WiLd. Small bowel review - Part II. Can J Gastroenterol 1997;11(2):159. 165. The small bowel has undergone intense study. Part II of this review of the small bowel summarizes the current knowledge about the permeability of the gastrointestinal epithelium; the brush border membrane; motility; carbohydrates; diabetes; ethanol; diet; and diagnostic procedures.
\end{abstract}

Key Words: Brush border membrane, Carbohydrates, Diabetes, Ethanol, Motility, Permeability, Small bowel

\section{Vue d'ensemble du grêle - deuxième partie}

RÉSUMÉ : L'intestin grêle a fait l'objet d'études approfondies. La deuxième partie de cette synthèse sur l'intestin grêle résume les connaissances accumulées à ce jour au sujet de la perméabilité de l'épithélium gastro-intestinal, de la bordure en brosse, de la motilité, des glucides, du diabète, de l'éthanol, des régimes alimentaires et des techniques diagnostiques.

$\mathrm{T}$ he small bowel has been the focus of intense study. In this second part of a review of the small bowel, the permeability of the gastrointestinal epithelium, the brush border membrane (BBM), motility, carbohydrates, diabetes, ethanol, diet and diagnostic procedures are examined.

\section{PERMEABILITY}

The permeability of the gastrointestinal epithelium can be modulated by a variety of factors including tissue $\mathrm{pH}$, adenosine $3^{\prime}, 5^{\prime}$-cyclic monophosphate, insulin, insulin-like growth factors, cytokines and activators of protein kinase C. Nitric oxide may also be a modulator of the permeability of tight junctions in Caco-2 monolayers (1). This effect of nitric oxide may be achieved by a reduction of epithelial ATP levels, and in vivo nitric oxide may preserve normal intestinal epithelial permeability by suppressing the release of other mediators from mast cells such as histamine and platelet-activating factor.

Clinical tests of intestinal permeability have been used to assess the presence of mucosal damage. A variety of different markers are used; it is generally recommended to use two probes, such as lactulose and mannitol, or polyethylene glycol-400 and ${ }^{51} \mathrm{Cr}$-EDTA. Increased permeability of the

intestine is noted in patients with a variety of intestinal disorders, such as nonsteroidal anti-inflammatory drug gastropathy, celiac sprue or Crohn's disease; in fact, increased permeability is noted in macroscopically normal small bowel of patients with Crohn's disease (2). The heightened intestinal permeability observed in some relatives of Crohn's disease patients is associated with increased CD45RO expression (3). The progressive decline in the ability to excrete lactulose and mannitol with increasing age is attributed to a change in renal function, rather than to an alteration in the 'leakiness' of the intestine (4).

The reference values of the lactulose/mannitol test have been determined for children and adults (5). The repeatability of the test and of the laboratory assay for the sugar absorption test is good. Validation of this test makes it a simple, noninvasive and reliable intestinal permeability test with potential applications in clinical practice.

Lactulose and mannitol, when given by mouth and measured subsequently in the urine, may be used as indirect measures of intestinal permeability and villous atrophy. Variations between predicted lactulose:mannitol recovery ratios (based on differences in diffusion ratios) and those observed with urinary recovery may be due to a heterogeneous intesti-

Nutrition and Metabolism Research Group, Division of Gastroenterology, Department of Medicine, University of Alberta, Edmonton, Alberta; Department of Medicine, Division of Gastroenterology, Department of Anatomy and Cell Biology, McGill University, Montreal, Quebec

Correspondence: Dr ABR Thomson, University of Alberta, 519 Robert Newton Research Building, Edmonton, Alberta T6G 2C2. Telephone 403-492-6490, fax 403-492-7964, e-mail alan.thomson@ualberta.ca

Received for publication January 2, 1996. Accepted April 10, 1996 
nal epithelial layer, with many more small pores permitting the diffusion of mannitol while excluding the passage of lactulose because of a relatively smaller population of larger pores. The intestinal permeability to lactulose and mannitol measured in vitro in Ussing chambers is approximately similar in all species studied, except for the wide variations and relatively low lactulose:mannitol urinary recovery ratios in cats and humans (6). This interspecies variation of urinary recovery of mannitol is caused by differences specific for the intact small intestine in vivo and may be due to hyperosmolality of villous tips in certain species, resulting in solvent drag through pores that allow diffusion of mannitol but not lactulose.

Increasing the flow of fluid through the human intestine (from 2.5 to $20 \mathrm{~mL} / \mathrm{min}$ ) decreases the L-xylose:urea permeability ratios and decreases the average calculated pore radius of the diffusion pathway from $130 \mathrm{~nm}$ to $80 \mathrm{~nm}$ (7). Increasing rates of perfusion may recruit enterocytes from along the sides of the villi; perhaps the cells lining the sides of the villi are less permeable than cells lining the villus tips.

The uptake of intact macromolecules plays an important role in immune surveillance and the development of systemic tolerance, and may contribute to the development of intestinal anaphylaxis. This permeation may occur through $\mathrm{M}$ cells overlying Peyer's patches and by a transcellular route, with endocytotic uptake of macromolecules. The transport of intact macromolecules is a saturable, energydependent process that uses the intracellular microtubular network and is regulated by the enteric nervous system, primarily through cholinergic nerves acting on muscarinic receptors (8). The permeability of the intestine is influenced by the function of the tight junctions, and the drug colchicine increases intestinal permeability by preventing the assembly of microtubules (9).

Intestinal ischemia, radiation injury, damage by cytotoxic agents, starvation and villous atrophy all may lead to damage to the intestinal barrier. The development of sepsis and systemic multi-organ failure in certain groups of critically ill patients may be the result of impaired intestinal barrier function to bacterial translocation. Bacterial translocation occurs in approximately $5 \%$ of general surgical patients (10). In vivo bacterial translocation occurs with experimental endotoxemia (11). Sepsis and endotoxemia stimulate cellular proliferation in the mucosa of the small intestine, a process partially mediated by interleukin 1-alpha (12). Increased intestinal permeability also occurs in association with burn injury, and supplementation of an elemental enteral diet with the dipeptide alanyl-glutamine decreases bacterial translocation in burned mice (13). Commercial enteral diets containing fibre and high concentrations of glutamine reduce bacterial translocation in this animal model (14). There is a metabolic regulation of bloodflow and oxygen supply to the gastrointestinal mucosa, which may be related to the countercurrent arrangement of microvessels in conjunction with vasomotion (15). Nitric oxide-derived urinary nitrate serves as a marker of intestinal bacterial translocation in rats (16). This may prove to be a useful quantitative noninvasive biomarker of intestinal bacterial translocation if similar findings are noted in humans.

\section{BBM}

Ultrastructural studies have shown that the intestinal epithelium is coated with a layer of filamentous glycocalyx, consisting of a mucin-type protein, radiating from the tips of microvilli layer (17). The BBM is supported by a bundle of actin microfilaments containing several actin-binding proteins, including two $\mathrm{F}$ actin cross-linkers (villin and fimbrin) and a protein complex composed of myosin I associated with three to four molecules of calmodulin that connect the $\mathrm{F}$ actin bundles to the BBM. The individual cytoskeletal proteins are recruited in a stepwise fashion. Suppressing villin expression using antisense RNA technology impairs the apical localization of the BBM sucrase-isomaltase complex (18), suggesting that the BBM morphogenesis may be important for the organization of certain proteins.

The role of membrane organization in plasma membrane solute transport has been reviewed (19). Newly synthesized proteins destined for the BBM are directed by an apical targeting mechanism that relies on some membrane component of the BBM, as well as on the trans-Golgi network glycosylphosphatidyl inositol-anchored plasma membrane protein. This complex becomes part of the BBM glycolipid 'rafts', which move to the apical membrane (20). Increased solute carrier-mediated transport may be the result of an alteration in the kinetic properties of individual transporters, possibly by reversible covalent modification by phosphorylation and by alterations in the rate of protein synthesis, with recruitment of pre-existing transporters regulated by cytoplasmic vesicle organization.

The sucrase-isomaltase complex is restricted to the intestinal BBM, and sucrase-isomaltase gene expression is influenced by dietary carbohydrates. Glucose uptake across the BBM is mediated by the sodium-dependent glucose transporter $\left(\mathrm{SGLT}_{1}\right)$. Intestinal glucose transport and $\mathrm{SGLT}_{1}$ mRNA levels are increased in animals fed a carbohydraterich diet; increased intake of medium chain triacylglycerol (MCT) also increases sucrase-isomaltase mRNA and SGLT 1 mRNA (21). When the composition of the diet changes at weaning there is coordinated modification and functional maturation of the small intestine, closure of the epithelium to macromolecules and appearance of jejunoileal differences, as well as expression of some digestive enzymes, such as sucrase-isomaltase, and the decline of others, such as lactasephlorizin hydrolase (LPH). These alterations appear to be an autonomous or 'hard wired' process that is modulated by the animal's hormonal status and the nature of dietary intake. When adult rats fast, there is an early increase in the expression of the proto-oncogenes c-fos and c-jun, reflecting the mitogenic response to refeeding, but differential changes occur in the expression of LPH and alkaline phosphatase (22). Starvation in the postnatal period in rats causes a precocious expression of sucrase-isomaltase activity and its mRNA, and is preceded by a transient burst of the expression of $c-f o s$, an event that is correlated to the ontogenic rise of 
c-fos mRNA which is observed before weaning (23). In contrast to the normal weaning condition, sucrase-isomaltase induction by starvation occurs without an obvious increase in epithelial cell proliferation, and patterns of sucrase-isomaltase activity and sucrase-isomaltase mRNA parallel the serum level of glucocorticoids. During refeeding, enterocytes that were committed to produce sucrase-isomaltase during starvation continue to express the enzyme while migrating up the villi, but the new epithelial cells arising from the crypts no longer synthesize sucrase-isomaltase, suggesting that the diet-induced changes are signalled in the crypt cells.

Development of BBM LPH and sucrase-isomaltase expression may be 'locally hard-wired', that is, controlled by a timing mechanism within the intestinal tissue. Exogenous glucocorticosteroid may advance the timing mechanism of normal intestinal development. 5-bromo-2-deoxyuridine substitutes for thymidine incorporation into genomic DNA and thereby results in the inhibition of maturation. Its paradoxical effect on glucocorticoid-induced maturation suggests that such maturation involves molecular mediators different from those associated with normal ontogeny (24).

Peroxidation of the intestinal BBM is associated with loss of nutrient transport function and an associated change in the physical properties of the membrane in which the physical transporter is embedded. The outer, compared with the inner, leaflet of the BBM is more susceptible to peroxidation injury (25).

\section{MOTILITY}

The enteric nervous system has been reviewed (26). During the fasting state there is a characteristic migrating myoelectric complex (MMC) that is disrupted by feeding. When given by mouth to rats, polyamines (ubiquitous low molecular weight polycations) disrupt intestinal MMCs and increase the frequency of colonic spike bursts (27). These exogenously administered polyamines act through the release of cholecystokinin (CCK), which interacts with its A and $\mathrm{B}$ receptors. Postprandial inhibition of MMCs in dog jejunum is mediated in part by a hormonal mechanism induced by the presence of food in the duodenum (28).

The important role of nitric oxide in the digestive system has been reviewed (29). Nitric oxide is an inhibitory transmitter of nonadrenergic noncholinergic neurons and its generation occurs in neural as well as in vascular components present in the wall of the rat intestine (30). Nitric oxide may be involved in the conversion of the MMC to the irregular electrical activity characteristic of the postprandial state (31). Nitric oxide is released from vascular endothelium under basal conditions and plays a role in the vasodilatory response to a number of stimuli (32). Nitric oxide has a proabsorptive influence; inhibition of endogenous nitric oxide synthesis causes secretion of water and ions (33). Also, inhibition of nitric oxide synthesis activates mast cells and increases epithelial permeability (34). This process is rapidly reversed with a nitric oxide donor and is prevented by pretreatment with an excess of nitric oxide's precursor,
L-arginine. Nitric oxide donors also improve mucosal function after prolonged hypothermic ischemia (35).

Hirschsprung's disease is characterized histologically by an absence of neuronal cell bodies in the affected portion of the intestine, and functionally by sustained contraction of the aganglionic segment. In the aganglionic bowel, nonadrenergic noncholinergic smooth muscle relaxation is absent. The enzyme responsible for nitric oxide formation is nitric oxide synthase. Nicotinamide adenine dinucleotide phosphate (NADPH)-diaphorase staining is a histochemical marker for nitric oxide synthase; absence of its positive staining in nerve fibres and an almost complete lack of nitric oxide synthase immunoreactivity are noted in the aganglionic bowel of patients with Hirschsprung's disease (36). The lack of nitric oxide-producing nerve fibres in the aganglionic intestine probably contributes to the inability of the smooth muscle to relax, thereby causing lack of peristalsis in patients with Hirschsprung's disease.

A rise in the concentration of intracellular calcium is essential for evoking contractile responses in the intestinal smooth muscle. The release of sequestered calcium initiates a rise in intracellular calcium as well as a contractile response dependent on the presence of extracellular calcium (37). The combination of calcium influx by receptor- and voltagegated calcium channels with calcium release from the sarcoplasmic reticulum results in increased intracellular calcium concentrations. Long term denervation of the intestine alters calcium metabolism at both the cell membrane and the sarcoplasmic reticulum of the smooth muscle cells of the longitudinal muscle layer (38).

Peripherally administered calcitonin inhibits canine gastrointestinal motility at the central nervous system level by lowering vagal activity (39). The myenteric circulation is responsive to adrenergic drugs, with resulting vasoconstriction in which there may be autoregulatory escape involving beta-adrenoceptor, purinergic and endothelial components (40).

Activation of muscarinic acetylcholine receptors present in the longitudinal muscle layer from the small intestine of the guinea pig increases the activity of phospholipase $\mathrm{C}$ via a $G$ protein. This causes the level of inositol $(1,4,5)$ triphosphate to increase and the triphosphate subsequently binds to its receptor on the sarcoplasmic reticulum, which serves as a channel to release calcium from stores into the cell. Smooth muscle relaxation occurs by lowering the intracellular concentration of calcium and by the dephosphorylation of myosin light chain. There is a reciprocal relationship between beta-adrenoceptors and muscarinic acetylcholine receptors, and diacylglycerols may exert a negative feedback inhibition on inositol phosphate production (41). Mucosal inflammation in the gut is associated with changes in motor activity, which is possibly related to increased expression of cytokines in the myenteric plexus and muscularis externa. Thus, with inflamed mucosa the intestinal smooth muscle cells are both targets for and sources of cytokines (42).

While patients with progressive systemic sclerosis (PSS) frequently have delayed esophageal transit or gastric empty- 
ing, only $40 \%$ have delayed mouth-to-cecum transit and $23 \%$ have prolonged whole gut transit. These motility changes may be associated with small bowel bacterial overgrowth (43).

Acute hyperglycemia in patients with diabetes mellitus reduces interdigestive contractility in the stomach and the small intestine, and euglycemic hyperinsulinemia abolishes antral phase III and makes duodenal phase III shorter, a process not affected by the beta-adrenergic receptors (44).

Erythromycin is capable of mimicking the effects of motilin in the proximal gastrointestinal tract, at least in part through its action as a motilin receptor agonist. Erythromycin has been used successfully in infants receiving prolonged parenteral nutrition for severe intestinal dysmotility after gastrointestinal surgery. In a child with neuropathic intestinal pseudo-obstruction, erythromycin induced a striking small intestinal monometric response (45). The further use of erythromycin in this setting needs to be explored, including in adults with pseudo-obstruction.

In patients with bulimia nervosa, gastrointestinal complaints range from bloating and flatulence in over $70 \%$ of patients to borborygmi and nausea in more than $40 \%$ (46). These common symptoms may be multiple and severe, and may improve with treatment, especially with management of the depression commonly associated with bulimia nervosa.

\section{CARBOHYDRATES}

$\mathrm{LPH}$ is the enzyme present in the BBM that hydrolyzes the milk sugar lactose. LPH activity is high at birth, but in many humans it declines after weaning. The clinical finding of milk intolerance due to LPH deficiency has a complex molecular basis. There are controversial reports about the levels of LPH mRNA in 'persistent' and in 'nonpersistent' individuals (47). There is marked heterogeneity of adult-type hypolactasia, with some enterocytes having neither LPH protein nor mRNA, some having no LPH protein but having LPH mRNA, some having LPH protein but no LPH activity and yet others having LPH activity, LPH protein and LPH mRNA (48). Clearly, different mechanisms control LPH expression in enterocytes on the same villus.

The BBM sucrase-isomaltase is inserted into the BBM as a single chain precursor. It is split into the heterodimeric sucrase-isomaltase by pancreatic proteases in the intestinal lumen. Pancreatic secretions are not essential for the processing of LPH or its precursor (49). The extensive post-translational modification of sucrase-isomaltase and LPH involves complex pathways. For example, the low rate of BBM sucrase-isomaltase synthesis reflects the slow rate at which the complex glycosylated single chain precursor is processed to the BBM form, sucrase-isomaltase (50).

Intestinal sugar absorption is mediated by the products of the $\mathrm{SGLT}_{1}$ gene or the glucose transporter (GLUT) gene. SGLT $_{1}$ is the sodium-dependent glucose transporter in the $\mathrm{BBM}, \mathrm{GLUT}_{5}$ is the sodium-independent fructose transporter in the BBM, and $\mathrm{GLUT}_{2}$ is the sodium-independent glucose and fructose transporter in the basolateral membrane (BLM). Passive permeation of sugars across the paracellular route also occurs (51). SGLT 1 handles hexoses with an equatorial hydroxyl group on C2. SGLT 1 is a glycosylated integral BBM protein with an apparent molecular mass of approximately $75 \mathrm{kDa}$. The $58 \mathrm{kDa}$ protein may be a SGLT 1 precursor protein that is incompletely glycosylated (52).

The activity and abundance of $\mathrm{SGLT}_{1}$ are regulated by dietary carbohydrates in nonruminants, eg, rats, and in ruminants, eg, lambs. Postweaning changes in $\mathrm{SGLT}_{1}$ protein in the lamb are not coordinated directly with fluctuations in the levels of $\mathrm{SGLT}_{1}$ mRNA. Glucose in the intestinal lumen leads to the synthesis of functional $\mathrm{SGLT}_{1}$; regulation is at the post-transcriptional level and is not determined by the cellular metabolism of hexoses. The sensing system for the dietary sugars appears to be on the external surface of the $\mathrm{BBM}$, and systemic factors do not appear to play a major role in signalling the regulation of the activity or expression of $\mathrm{SGLT}_{1}$. The signal-receiving site is likely located within the intestinal crypt although neural and paracrine mechanisms cannot be excluded.

Enriching the amount of fructose in the diet stimulates fructose uptake by GLUT 5 , with a lesser stimulation of glucose and galactose uptake; a $65 \%$ glucose diet increases both glucose and fructose uptake. Glucose, and to a lesser extent fructose, intake results in increased basolateral GLUT 2 protein (53). Because sucrose does not increase GLUT $_{5}$ protein levels there may be an alternative transport pathway in the small intestine for the monosaccharides generated from sucrose. The study of the regulation of these transporter proteins also has been undertaken in Caco-2 human cells in culture (54). In differentiated Caco-2 cells, fructose transport is inhibited by dMM, a specific alpha-mannosidase I inhibitor, whereas in undifferentiated cells it has no effect on mannose uptake (55).

When sugars are transported by GLUT2 across the BLM into the submucosal space, the osmolarity of the submucosal interstitium increases and there is functional vasodilation of the submucosal arterioles. There is also release of nitric oxide. While the lymphatic system may facilitate the distribution of hypertonic material in the bowel during absorption, glucose may be absorbed without a functional lymphatic system (56).

The perfusion with glucose of the basolateral (ie, the BLM) or the mucosal (ie, the BBM) side of the enterocyte stimulates the uptake of glucose, but the time taken for half-maximal stimulation of vascular uptake is 6.3 mins, which precedes the inhibition of luminal uptake by 6.5 mins (57). Thus, the plasma glucose concentration may be one of the factors influencing glucose uptake and it appears that, at least for this signal, the initial site of action is on the vascular side of the enterocyte, ie, on the BLM. It is unknown how changes at one membrane signal an alteration in the transporter activity at another membrane (ie, how is $S_{G L T}$ in BBM signalled by altered GLUT 2 in BLM by hyperglycemia?).

Inhibiting polyamine synthesis with DFMO (alpha-difluoromethylornithine) reduces the maximal transport rate (Vmax) for glucose uptake in the BBM, and this inhibitory 
effect is prevented by oral administration of the polyamine spermine, spermidine or putrescine. When spermine is given alone, the Vmax for glucose uptake increases, whereas spermidine and putrescine together decrease the value of Vmax by a process not dependent on protein synthesis or membrane lipid composition (58).

\section{DIABETES}

Insulinopenic diabetes mellitus is associated with increased enterocyte expression of $\mathrm{SGLT}_{1}, \mathrm{GLUT}_{5}$ and $\mathrm{GLUT}_{2}$, as well as their respective mRNAs (59). After induction of diabetes there is expression of the mRNAs encoding these nutrient transporters in lower villus and crypt enterocytes, suggesting that the enhanced absorption of sugars in diabetes is due not only to increased activity of existing transporters, but also to the premature expression of hexose transporters by enterocytes along the crypt-villus axis.

The increased glucose uptake that occurs in streptozotocin-induced diabetic rat intestine is associated with a decrease in the total activity and activity ratios of fructose 6-phosphate and 6-phosphofructo-1-kinase (60). The mechanistic link between diabetes-associated changes in sugar uptake and altered intracellular sugar metabolism is unclear.

\section{ETHANOL}

Ingestion of ethanol may cause gastrointestinal symptoms such as pain and diarrhea. The permeability of the intestine, as measured by mannitol absorption, is decreased with acute, but not with chronic, ethanol intake (61). Exposure of the jejunal lumen to concentrations of alcohol similar to those seen in the human intestine during moderate drinking results in alterations in the intestinal microvasculature, as well as morphological changes including contraction of the villous core, shortening of the villus and separation of the epithelium from the basal lamina by accumulation of subepithelial fluid. Similar morphological changes have been shown on video microscopy in both in vitro and in vivo preparations. It is likely that the ethanol-associated changes in morphology are independent of its actions on the microcirculation (62).

Maternal alcohol consumption can adversely affect the fetus, leading to intra-uterine and postnatal growth retardation, dysfunction of the central nervous system and a variety of organ malformations. During the third trimester the human fetus swallows large volumes of amniotic fluid, and it is during this time that the BBM disaccharidases normally begin to mature. In a rabbit model of maternal ethanol ingestion, intra-uterine growth retardation and postnatal growth failure are observed, in association with a lower activity of BBM lactase (63).

\section{DIET}

Glutamine is the major energy source for enterocytes, which are responsible for most of the intestinal metabolism of glutamine (64). An important role of glutamine metabolism in the small intestine is to produce citrulline, the precursor of renal arginine, which is important in adults as well in neonates (65). With malnutrition or after major trauma when glutamine concentrations in tissue are decreased - the barrier function of the intestine may be impaired, and glutamine administration may improve this abnormal increased permeability (66). Arginine becomes an essential amino acid during growth and catabolic states, and supplementation of the diet with arginine (a precursor of nitric oxide) or with alpha-ketoglutarate (an arginine precursor) may help support the barrier function of the intestine (67).

Traumatized patients may have fewer infections when they are treated with enteral nutrition (68), possibly due to reduced bacterial translocation (69). Dietary fibre may reduce the deleterious effect of endotoxin or protein energy malnutrition on intestinal bacterial translocation. Fermentation of dietary fibre leads to the production of short chain fatty acids (SCFAs), and fibre increases substrate oxidation by isolated colonocytes but not by distal small intestinal enterocytes (70). SCFAs stimulate colonic absorption and promote adaptation in response to small intestinal resection (71). The jejunotrophic effects of cecally infused SCFAs are mediated by the afferent arm of the automonic nervous system and are associated with increased jejunal concentrations of gastrin (72). Thus, the large intestine may be important in the digestion of carbohydrates and in the salvage of calories in patients with the short bowel syndrome (73).

It is controversial whether enteral nutrition supplements reduce morbidity and mortality rates due to infections in critically ill patients, but giving burned and postoperative cancer patients these formulations decreases the risk of infections (74). Ingestion of MCT increases the jejunal mucosal mass, BBM phospholipids and activities of alkaline phosphatase and sucrase (75). Compared with rats fed MCT, rats fed long chain triglycerides showed greater increases in mucosal weight, protein and DNA in the remaining intestine after $60 \%$ resection (76).

The IEC-6 cell line, derived from rat intestinal crypt cells, appears to be a good in vitro model to study the feasibility and dynamics of retroviral gene transfer in intestinal cells (77). This model system should be helpful in devising strategies for gene transfer into intestinal epithelium using retroviral vectors.

\section{DIAGNOSTIC PROCEDURES}

The plain film of the abdomen has limited sensitivity (52\%) and specificity $(71 \%)$ for the distinction of the presence of a mechanical obstruction versus a nondynamic obstruction of the intestine, although the positive predictive value (86\%) increases as the air-fluid level height increases above $20 \mathrm{~mm}$ (78). When a computed tomographic scan of the abdomen is used for diagnosing complete obstruction of the small bowel, the sensitivity for small bowel obstruction was 100\% (79). Enteroclysis may be useful to determine the cause and presence of enteric intussusception in the adult (80).

The steatocrit method has recently been introduced as a simple screening test to diagnose steatorrhea. The value of the steatocrit increases with the degree of fecal acidification, and acidification of fecal homogenates leads to a marked 
improvement in the steatocrit method (81). However, how reliable this test is, compared with the $72 \mathrm{~h}$ stool collection with measurement of fecal fat, remains controversial. The hydrogen breath test with $25 \mathrm{~g}$ D-xylose, with collection of hydrogen in the breath for $5 \mathrm{~h}$, is more sensitive than the $3 \mathrm{~h}$ test to detect malabsorption (82). Glycosyl ureides are condensation products of reducing sugars and urea, which resist cleavage by BBM enzymes and are split by colonic flora.

ACKNOWLEDGEMENTS: The authors thank Chandra Messier for her much appreciated skill in typing the manuscript.

\section{REFERENCES}

1. Salzman AL, Menconi MJ, Unno N, et al. Nitric oxide dilates tight junctions and depletes ATP in cultured Caco-2BBe intestinal epithelial monolayers. Am J Physiol 1995;268:G361-73.

2. Peeters M, Ghoos YVO, Maes B, et al. Increased permeability of macroscopically normal small bowel in Crohn's disease. Dig Dis Sci 1994;39:2170-6.

3. Yacyshyn BR, Meddings JB. CD45RO expression on circulating $\mathrm{CD} 19^{+} \mathrm{B}$ cells in Crohn's disease correlates with intestinal permeability. Gastroenterology 1995;108:132-7.

4. Saltzman JR, Kowdley KV, Perrone G, Russell RM. Changes in small-intestine permeability with aging. J Am Geriatr Soc 1995;43:160-4.

5. Van Elburg RM, Uil JJ, Kokke FTM, et al. Repeatability of the sugar-absorption test, using lactulose and mannitol, for measuring intestinal permeability for sugars. J Pediatr Gastroenterol Nutr 1995;20:184.

6. Bijlsma PB, Peeters RA, Groot JA, Dekker PR, Taminiau JAJM, Van Der Meer R. Differential in vivo and in vitro intestinal permeability to lactulose and mannitol in animals and humans: a hypothesis. Gastroenterology 1995;108:687-96.

7. Fine KD, Santa Ana CA, Porter JL, Fordtan JS. Effect of changing intestinal flow rate on a measurement of intestinal permeability. Gastroenterology 1995;108:983-9.

8. Kimm MH, Curtis GH, Hardin JA, Gall DG. Transport of bovine serum albumin across rat jejunum: role of the enteric nervous system. Am J Physiol 1994;266:G186-93.

9. Fradkin A, Yahav J, Diver-Haber A, Zemer D, Jonas A. Colchicine induces enhanced intestinal permeability in the rat. Acta Physiol Scand 1995;153:249-54.

10. Sedman PC, Macfie J, Sagar P, et al. The prevalence of gut translocation in humans. Gastroenterology 1994;107:643-9.

11. Go LL, Healey PJ, Watkins SC, Simmons RL, Rowe MI. The effect of endotoxin on intestinal mucosal permeability to bacteria in vitro. Arch Surg 1995;130:53-8.

12. Rafferty JF, Noguchi Y, Rischer JE, Hasselgren P-O. Sepsis in rats stimulates cellular proliferation in the mucosa of the small intestine. Gastroenterology 1994;107:121-7.

13. Tenenhaus M, Hansbrough JF, Zapata-Sirvent RL, Ohara M, Nyhan W. Supplementation of an elemental enteral diet with alanyl-glutamine decreases bacterial translocation in burned mice. Burns 1994;20:220-5.

14. Zapata-Sirvent RL, Hansbrough JF, Ohara MM, Rice-Asaro M, Nyhan WL. Bacterial translocation in burned mice after administration of various diets including fiber- and glutamine-enriched enteral formulas. Crit Care Med 1994;22:690-6.

15. Hasibeder W, Germann R, Sparr H, et al. Vasomotion induces regular major oscillations in jejunal mucosal tissue oxygenation. Am J Physiol 1994:266:G978-86.

16. Oudenhoven IMJ, Klaasen HLBM, Lapre JA, Keerkamp AH, VanDerMeer R. Nitric oxide-derived urinary nitrate as a marker of intestinal bacterial translocation in rats. Gastroenterology 1994;107:47-53.

17. Maury J, Nicoletti C, Guzzo-Chambraud L, Maroux S. The filamentous brush border glylcocalyx, a mucin-like marker of enterocyte hyper-polarization. Eur J Biochem 1995;228:323-31.

18. Costa de Beauregard MA, Pringault E, Robine S, Louvard D. Suppression of villin expression by antisense RNA impairs brush border assembly in polarized epithelial intestinal cells. EMBO J 1995;14:409-21.
${ }^{13} \mathrm{C}$-labelled glycosyl ureides may be a useful nonevasive marker of intestinal transit (83).

The measurement of urinary LTE4 is a useful test for monitoring the activation of peptidoleukotrienes in children with Crohn's disease (84). This test provides a noninvasive, objective adjuvant for the assessment of inflammatory disease activity. It needs to be evaluated prospectively in children as well as adults with inflammatory bowel diseases.

19. Bradbury NA, Bridges RJ. Role of membrane trafficking in plasma membrane solute transport. Am J Physiol 1995;267:C1-24.

20. Danielsen EM. Involvement of detergent-insoluble complexes in the intracellular transport of intestinal brush border enzymes. Biochemistry 1995;34:1596-605.

21. Yasutake H, Goda T, Takase S. Dietary regulation of sucrase-isomaltase gene expression in rat jejunum. Biochim Biophys Acta 1995;1243:270-6.

22. Hodin RA, Graham J, Meng S, Upton M. Temporal pattern of rat small intestinal gene expression with refeeding. Am J Physiol 1994;266:G83-9.

23. Nsi-Emvo E, Foltzer-Jourdainne C, Raul F, et al. Precocious and reversible expression of sucrase-isomaltase unrelated to intestinal cell turnover. Am J Physiol 1994;266:G568-75.

24. Nanthakumar NN, Henning SJ. Distinguishing normal and glucocorticoid-induced maturation of intestine using bromodeoxyuridine. Am J Physiol 1995;268:G139-45.

25. Jourd'Heuil D, Mehta S, Meddings JB. Hemileaflet susceptibility to oxidative damage in the intestinal brush-border membrane. Am J Physiol 1995;268:G260-9.

26. Costa M, Brookes SJH. The enteric nervous system. Am J Gastroenterol 1994;89:S129-37.

27. Fioramonti J, Fargeas M-J, Bertrand V, Pradayrol L, Bueno L. Induction of postprandial intestinal motility and release of cholecystokinin by polyamines in rats. Am J Physiol 1994;267:G960-5.

28. Behrns KE, Sarr MG. Duodenal nutrients inhibit canine jejunal fasting motor patterns through a hormonal mechanism. Dig Dis Sci 1994;39:1665-71.

29. Konturek SK, Konturek PC. Role of nitric oxide in the digestive system. Digestion 1995;56:1-13.

30. Nichols K, Staines W, Krantis A. Nitric oxide synthase distribution in the rat intestine: A histochemical analysis. Gastroenterol 1993;105:1651-61.

31. Rodriguez-Membrilla A, Jimenez MM, Gonalons E, Vergara P. Is nitric oxide the final mediator regulating the migrating myoelectric complex cycle? Am J Physiol 1995;268:G207-14.

32. Nichols K, Staines W, Rubin S, Krantis A. Distribution of nitric oxide synthase activity in arterioles and venules of rat and human intestine. Am J Physiol 1994;267:G270-5.

33. Barry MK, Aloisi JD, Pickering SP, Yeo CJ. Nitric oxide modulates water and electrolyte transport in the ileum. Ann Surg 1994;219:382-8.

34. Kanwar S, Wallace JL, Befus D, Kubes P. Nitric oxide synthesis inhibition increases epithelial permeability via mast cells. Am J Physiol 1994;266:G222-9.

35. Villarreal D, Grisham MB, Granger DN. Nitric oxide doonors improve gut function after prolonged hypothermic ischemia. Transplantation 1995;59:685-9.

36. Larsson LT, Shen Z, Ekblad E, Sundler F, Alm P, Andersson KE. Lack of neuronal nitric oxide synthase in nerve fibers of aganglionic intestine: A clue to Hirschsprung's disease. J Pediatr Gastroenterol Nutr 1995;20:49-53.

37. Ohta T, Kawai K, Ito S, Nakazato Y. $\mathrm{Ca}^{2+}$ entry activated by emptying of intracellular $\mathrm{Ca}^{2+}$ stores in ileal smooth muscle of the rat. Br J Pharmacol 1995;114:1165-70.

38. Osinski MA, Bass P. Myenteric denervation of rat jejunum alters calcium responsiveness of intestinal smooth muscle. Gastroenterology 1995;108:1629-36.

39. Nakamura H, Asano T, Haruta K, Takeda K. Gastrointestinal motor inhibtion by exogenous human, salmon, and eel calcitonin in conscious dogs. Can J Physiol Pharmacol 1995;73:43-9.

40. Remak G, Hottenstein OD, Jacobson ED. Adrenergic, purinergic, and endothelial mediators and modulators of morepinephrine-induced mesenteric autoregulatory escape. Dig Dis Sci 1994;39:1655-64. 
41. Prestwich SA, Bolton TB. Inhibition of muscarinic receptor-induced inositol phospholipid hydrolysis by caffeine, $\beta$-adrenoceptors and protein kinase $\mathrm{C}$ in intestinal smooth muscle. $\mathrm{Br} \mathrm{J}$ Pharmacol 1995;114:602-11.

42. Khan I, Blennerhassett MG, Kataeva GV, Collins SM. Interleukin $1 \beta$ induces the expression of interleukin 6 in rat intestinal smooth muscle cells. Gastroenterol 1995;108:1720-8.

43. Wegener M, Adamek RJ, Wedmann B, Jergas M, Altmeyer P. Gastrointestinal transit through esophagus, stomach, small and large intestine in patients with progressive systemic sclerosis. Dig Dis Sci 1994:39:2209-15.

44. Bjornsson ES, Urbanavicius V, Eliasson B, Attvall S, Smith U, Abrahamsson $\mathrm{H}$. Effects of insulin and beta-adrenergic blockade on the migrating motor complex in humans. Scand J Gastroenterol 1995;30:219-24.

45. Simkiss DE, Adams IP, Myrdal U, Booth IW. Erythromycin in neonatal postoperative intestinal dysmotility. Arch Dis Child 1994;71:F128-9.

46. Chami TN, Andersen AE, Crowell MD, Schuster MM, Whitehead WE. Gastrointestinal symptoms in bulimia nervosa: Effects of treatment. Am J Gastroenterol 1995;90:88-92.

47. Harvey CB, Wang Y, Hughes LA, et al. Studies on the expression of intestinal lactase in different individuals. Gut 1995;36:28-33.

48. Maiuri L, Rossi M, Raia V, et al. Mosaic regulation of lactase in human adult-type hypolactasia. Gastroenterology 1994;107:54-60.

49. Keller P, Poiree J-C, Giudicelli J, Semenza G. Do pancreatic proteases play a role in processing prolactase and/or in the postweaning decline of lactase? Am J Physiol 1995;268:G41-6.

50. Dudley MA, Jahoor F, Burrin DG, Reeds PJ. Brush-border disaccharidase synthesis in infant pigs measured in vivo with $\left[{ }^{2} \mathrm{H}_{3}\right]$ leucine. Am J Physiol 1994;267:G1128-34.

51. Karasov WH, Cork SJ. Glucose absorption by a nectarivorous bird: the passive pathway is paramount. Am J Physiol 1994;267:G18-26.

52. Shirazi-Beechey SP, Gribble SM, Wood IS, et al. Dietary regulation of the intestinal sodium-dependent glucose cotransporter (SGLT1). Biochem Soc Trans 1994;22:655-8.

53. Burant CF, Saxena M. Rapid reversible substrate regulation of fructose transporter expression in rat small intestine and kidney. Am J Physiol 1994;267:G71-9.

54. Mesonero J, Mahraoui L, Matosin M, Rodolosse A, Rousset M, Brot-Laroche E. Expression of the hexose transporters GLUT1-GLUT5 and SGLT1 in clones of Caco-2 cells. Biochem Soc Trans 1994;22:681-4.

55. Ogier-Denis E, Blais A, Houri J-J, Voisin T, Trugnan G, Codogno P. The emergence of a basolateral 1-deoxymannojiuimycin-sensitive mannose carrier is a function of intestinal epithelial cell differentiation. J Biol Chem 1994:269:4285-90.

56. Steenbergen JM, Lash JM, Bohlen HG. Role of a lymphatic system in glucose absorption and the accompanying microvascular hyperemia. Am J Physiol 1994;267:G529-35.

57. Pennington AM, Corpe CP, Kellett GL. Rapid regulation of rat jejunal glucose transport by insulin in a luminally and vascularly perfused preparation. J Physiol 1994;478:187-93.

58. Johnson LR, Brockway PD, Madsen K, Hardin JA, Gall DG. Polyamines alter intestinal glucose transport. Am J Physiol 1995;268:G416-23.

59. Burant CF, Flink S, DePaoli AM, et al. Small intestine hexose transport in experimental diabetes. J Clin Invest 1994;93:578-85.

60. Madsen KL, Ariano D, Fedorak RN. Vanadate treatment rapidly improves glucose transport and activates 6-phosphofructo-1-kinase in diabetic rat intestine. Diabetologia 1994;38:403-12.

61. Keshavarzian A, Fields JZ, Vaeth J, Holmes EW. The differing effects of acute and chronic alcohol on gastric and intestinal permeability. Am J Gastroenterol 1994;89:2205-11.

62. Dinda PK, Buell MG, Morris O, Beck IT. Studies on ethanol-induced subepithelial fluid accumulation and jejunal villus bleb formation. An in vitro video microscopic approach. Can J Physiol Pharmacol 1994;72:1186-92.

63. Guo W, Gregg JP, Fonkalsrud EW. Effect of maternal ethanol intake on fetal rabbit gastrointestinal development. J Pediatr Surg 1994;29:1030-4.

64. Newsholme EA, Carrie AL. Quantitive aspects of glucose and glutamine metabolism by intestinal cells. Gut 1994;1(Suppl):S13-7.

65. Wu G, Knabe DA, Yan W, Flynn NE. Glutamine and glucose metabolism in enterocytes of the neonatal pig. Am J Physiol 1995;68:R334-42.

66. Wiren M, Magnusson KE, Larsson J. Enteral glutamine increases growth and absorptive capacity of intestinal mucosa in the malnourished rat. Scand J Gastroenterol 1995;30:146-52.

67. Cynober L. Can arginine and ornithine support gut functions? Gut 1994;1(Suppl):S42-5.

68. Kudsk KA. Gut mucosal nutritional support - enteral nutrition as primary therapy after multiple system trauma. Gut 1994;1(Suppl):S52-4.

69. Van Leeuwen PAM, Boermeester MA, Houdijk APJ, et al. Clinical significance of translocation. Gut 1994;1(Suppl):S28-34.

70. Marsman KE, McBurney MI. Dietary fiber increases oxidative metabolism in colonocytes but not in distal small intestinal enterocytes isolated from rats. J Nutr 1995;125:273-82.

71. Scheppach W. Effects of short chain fatty acids on gut morphology and function. Gut 1994;1:S35-8.

72. Frankel WL, Zhang W, Singh A, et al. Mediation of the trophic effects of short-chain fatty acids on the rat jejunum and colon. Gastroenterology 1994;106:375-80.

73. Nordgaard I, Hansen BS, Mortensen PB. Colon as a digestive organ in patients with short bowel. Lancet 1994;343:378-6.

74. Heyland DK, Cook DJ, Guyatt GH. Does the formulation of enteral feeding products influence infectious morbidity and mortality rates in the critically ill patient? A critical review of the evidence. Crit Care Med 1994;22:1192-202.

75. Schwartz S, Farriol M, Garcia-Arumi E, Andreu AL, Hellin JL, Arbos MA. Effect of medium chain triglycerides (MCT) on jejunal mucosa mass and protein synthesis. Gut 1994;1:S39-41.

76. Chen WJ, Yang CL, Lai HS, Chen KM. Effects of lipids on intestinal adaptation following 60\% resection in rats. J Surg Res 1995;58:253-9.

77. Noel RA, Shukla P, Henning SJ. Optimization of gene transfer into intestinal epithelial cells using a retroviral vector. J Pediatr Gastroenterol Nutr 1994;19:43-9.

78. Harlow CL, Stears RLG, Zeligman BE, Archer PG. Diagnosis of bowel obstruction on plain abdominal radiographs: Significance of air-fluid levels at different heights in the same loop of bowel. Am J Roentgenol 1993;161:291-5.

79. Frager D, Medwid SW, Baer JW, Mollinelli B, Friedman M. CT of small-bowel obstruction: Value in establishing the diagnosis and determing the degree and cause. Am J Roentgenol 1994;162:37-41.

80. Gourtsoyiannis NC, Papakonstantinou O, Bays D, Malamas M. Adult enteric intussusception: additional observations on enteroclysis. Abdom Imaging 1994;19:11-7.

81. Tran M, Forget P, Van den Neucker A, Strik J, van Dreel B, Kuijten R. The acid steatocrit: A much improved method. J Pediatr Gastroenterol Nutr 1994;19:299-303.

82. Casellas F, Malagelada J-R. Clinical applicability of shortened D-xylose breath test for diagnosis of intestinal malabsorption. Dig Dis Sci 1994;39:2320-6.

83. Heine WE, Berthold HK, Klein PD. A novel stable isotope breath test: ${ }^{13} \mathrm{C}$-labeled glycosyl ureides used as noninvasive markers of intestinal transit time. Am J Gastroenterol 1995;90:93-8.

84. Kim JH, Tagari P, Griffiths AM, Ford-Hutchinson A, Smith C, Sherman PM. Levels of peptidoleukotriene E4 are elevated in active Crohn's disease. J Pediatr Gastroenterol Nutr 1995;20:403-7. 


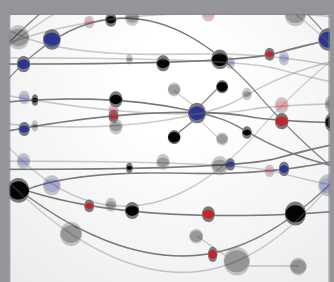

The Scientific World Journal
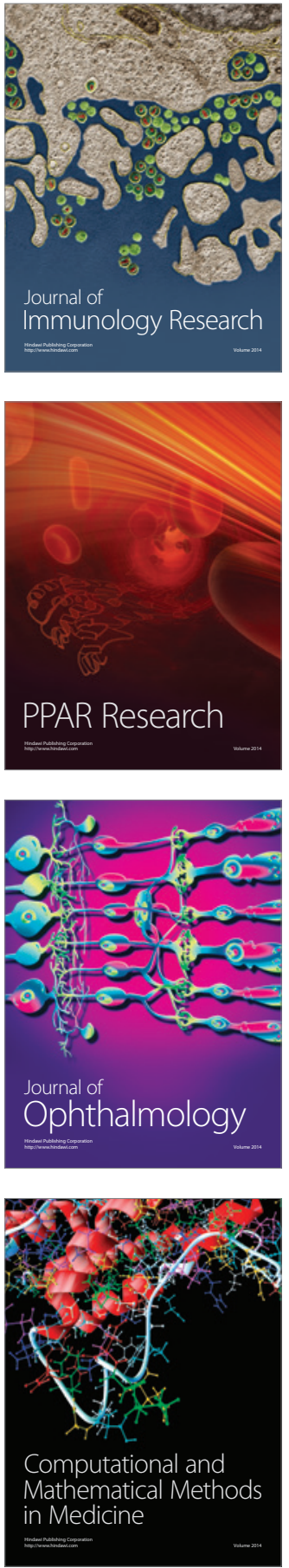

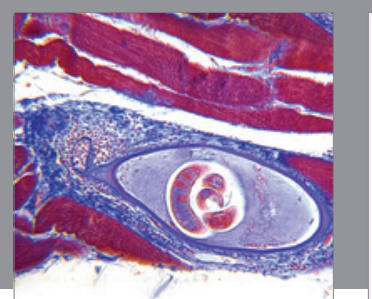

Gastroenterology Research and Practice

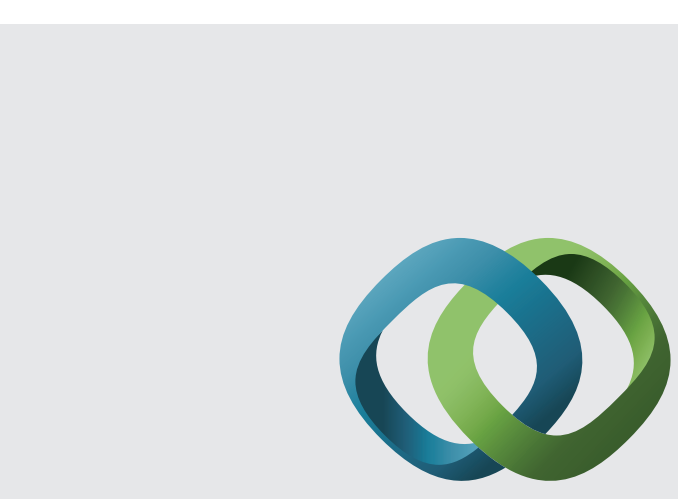

\section{Hindawi}

Submit your manuscripts at

http://www.hindawi.com
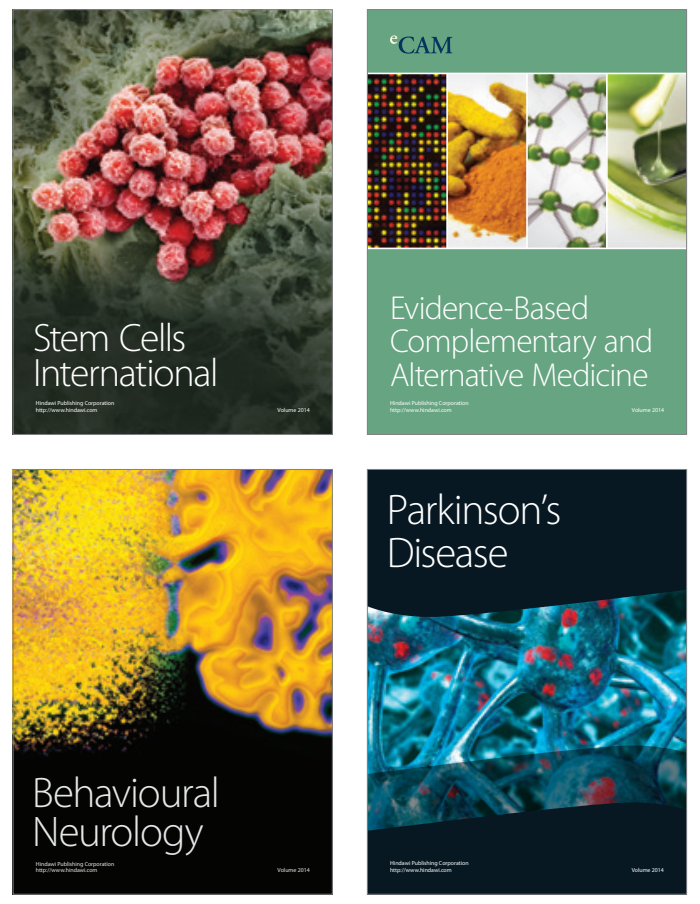
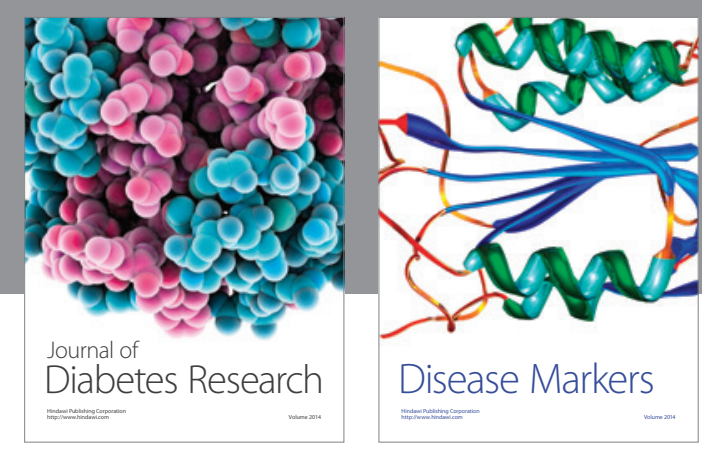

Disease Markers
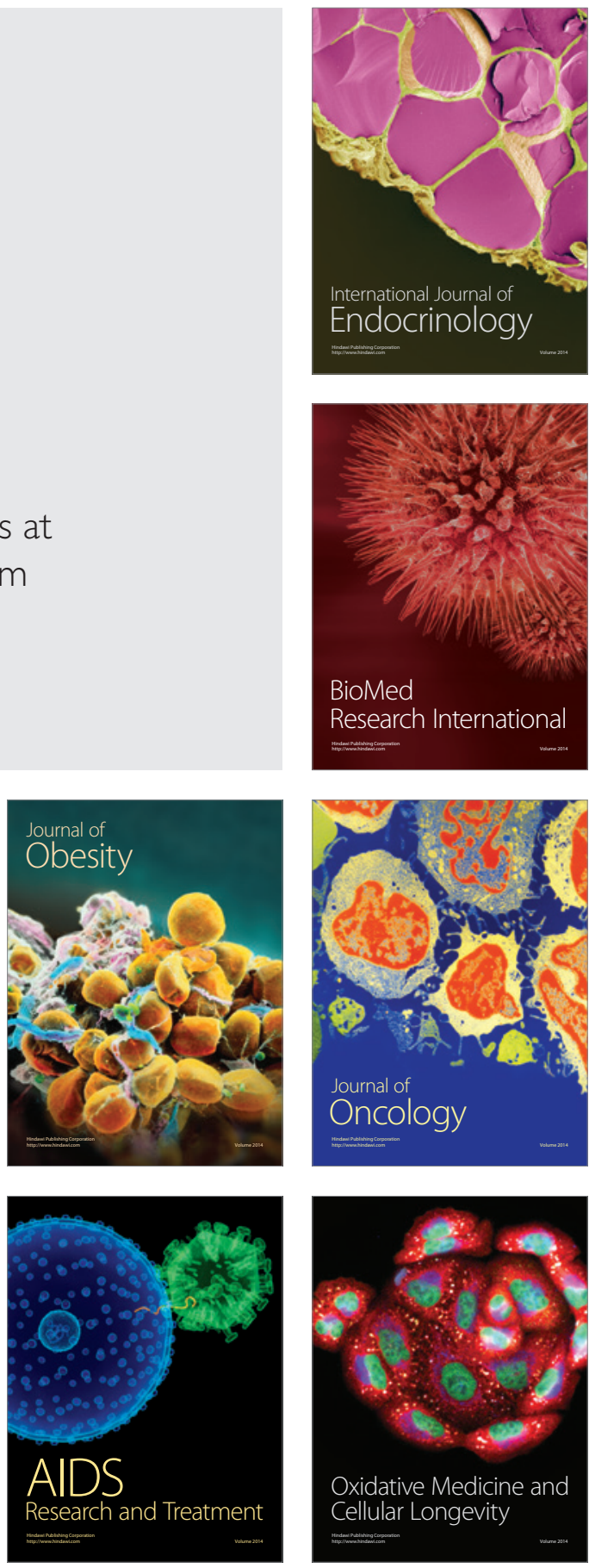